
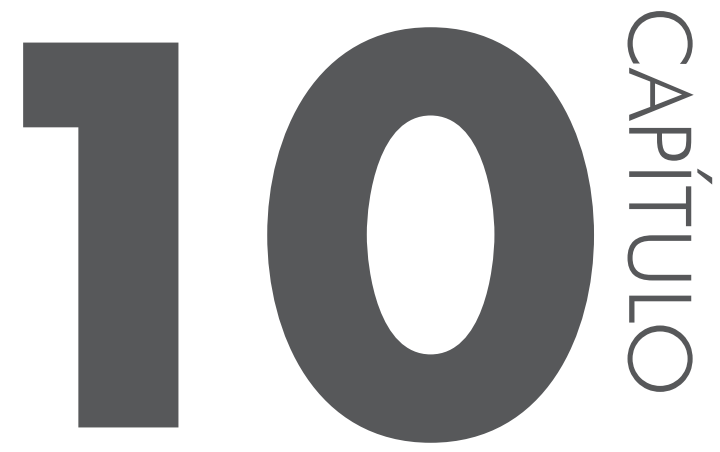

\title{
A prática de ensino de literatura na escola
}

Flavio da Rocha ${ }^{1}$

Olga Maria Vieira de Souza ${ }^{2}$

\subsection{Introdução}

O presente artigo tem como objetivo ressaltar o ensino de literatura ministrados nas escolas brasileiras, considerando as adversidades no conjunto da sociedade que engloba e como isso se reflete no ensino-aprendizagem do aluno.

Ao entrarmos num estudo que envolve a política educacional, estaremos voltados para uma complexa estrutura, na qual o Estado, propulsor de diversos mecanismos que farão refletir resultados dentro do cotidiano escolar, corrobora

1 Graduando em Letras pela Universidade Federal Fluminense (UFF).

2 Graduanda em Letras pela Universidade Federal Fluminense (UFF). 
para uma diminuição destes. Essas estruturas educacionais são influenciadas por um governo problemático, que ignora os pontos importantes para a construção de bases educacionais de um ensino de qualidade.

\subsection{Reflexões teóricas e sociais}

O método de ensino aplica-se diante da vivência de um grupo de alunos que, juntos, têm acesso ilimitado a recursos disponíveis e é na forma de autogestão que os alunos buscarão encontrar as bases mais satisfatórias de sua própria aprendizagem, sem qualquer forma de coerção. Trata-se de colocar nas mãos do aluno tudo o que for possível. Os estudantes têm liberdade de trabalhar ou não com o meio oferecido, permanecendo o interesse pedagógico na dependência de suas necessidades ou das do grupo.

Para o aluno, existe uma pedagogia impositiva, atual e praticada pelas instituições de ensino e pelo corpo docente, na qual o professor está centralizado como fonte superior de ensino e assim aplicando um método hierárquico no qual os alunos frequentam a escola para adquirir o conhecimento do professor, sem a oportunidade de manifestarem perante o material e as disciplinas impostas pela instituição escolar.

É preciso ouvir o aluno e dialogar sobre o material e as disciplinas a serem adotadas, pois os estudantes dos Ensinos Fundamental e Médio são os maiores receptores de uma educação falha e fragmentada que não visa auxiliar na melhor forma de se aplicar um conteúdo essencial para a formação do indivíduo e sim em atirar partes de conteúdos para uma fraca assimilação e memorização. As matérias escolares deveriam ser colocadas à disposição do aluno, mas não poderiam ser cobradas e impostas. As disciplinas escolares seriam um instrumento a mais, pois o que é realmente importante é o conhecimento que resulta das experiências vividas pelo grupo.

O Brasil tem uma riqueza vasta em seu território, desde a colonização até os dias de hoje. Para Buarque (2013), isso contribuiu para a nossa falta de preocupação em inovar em ideias e tecnologias, o que se refletiu em nossa educação. Segundo o autor, precisamos romper com a nossa ideia do "plantando tudo nela dá" para "em se aprendendo, nela tudo se cria” (BUARQUE, 2007, p. 20). Assim a nossa prioridade na exploração da terra e dos recursos naturais provindos dela nos deixaram para trás na corrida tecnológica e obviamente na educação.

Para Saviani (2008), a explicação da precariedade na educação brasileira vem de uma política econômico-capitalista voltada exclusivamente para o mercado, para a qual a educação, que faz parte do Estado, entraria como uma modalidade de política social mercadológica totalmente secundária, assim como a saúde e a previdência social. Sendo secundária, os investimentos na chamada política 
social sempre serão menores do que, por exemplo, investimentos em novas estradas para circular mercadorias para o crescimento da economia do país.

Assim, levando em consideração a precariedade e a falta de recursos para uma educação digna e de base para a construção de um indivíduo em formação, não podemos pensar em mudanças diretas na Educação, mas nas políticas educacionais para uma possível reforma, visando a qualidade do que será passado ao aluno posteriormente. $\mathrm{O}$ alicerce de uma política educacional é a mudança para uma infraestrutura mais fundamentada nos direitos dos estudantes e voltada para o interesse da comunidade escolar.

\subsection{Experiência discente}

O ambiente de experiência discente a ser aqui relatado envolve um pré-vestibular comunitário, denominado Pré-universitário Popular Curso Millennium, localizado no Liceu Nilo Peçanha, em Niterói. A disciplina ministrada envolve o ensino de literatura. No Pré-universitário Millennium, grande parte dos alunos provem de escolas públicas. Durante o período da experiência aqui relatada havia duas turmas, cada uma com aproximadamente vinte alunos.

As matérias pertinentes à literatura abrangiam as principais características de cada movimento e época literária, tendo em vista que o caráter exigido nos vestibulares permeia tal aspecto. Buscou-se constituir o conhecimento peculiar de cada autor e época baseado na experiência concreta dos alunos com o texto. Poesias e fragmentos de contos e romances eram lidos em sala, buscando a participação espontânea dos alunos, os quais puderam também experienciar um contato direto com os livros.

A experiência do toque na folha, nas ilustrações, na capa do livro foi ressaltada, tendo em vista que a literatura também se constrói em uma relação do corpo com o papel. Ainda que não se ofereça muita atenção a esse aspecto, acredita-se que existe algo próprio nas relações humanas com os instrumentos no que se refere às experiências sinestésicas. Sensações são sentidas por aquele que toca no livro. Sentidos como o olfato, o tato e a visão se combinam, produzindo uma experiência mais abrangente do que é literatura - porém, ressalta-se, esse aspecto é aquele do que não tem sentido, isto é, não há um significado que dê conta desse momento sinestésico, daí sua importância na ausência de algo racionalizável.

No início, ao longo das aulas, era feita uma primeira leitura do texto, em seguida, buscava-se ler novamente e problematizar o que estava escrito. No momento da problematização, os alunos revelavam seu interesse e começavam a ser enredados pela literatura. Compartilhavam suas visões de mundo e suas compreensões dos fragmentos. 
A experiência possibilitou a verificação de que uma aula envolvente dá-se tal como um texto. Ela deve tecer - construir - junto com os alunos possibilidades de interpretação e problematizações para as obras escolhidas, de forma que, nessa manobra, os alunos são tomados pelo interesse e redescobrem certo sabor na literatura.

Também se faz necessário expor as falhas desse percurso. Alguns alunos não conseguiram se envolver com as leituras trabalhadas em sala, ignorando ou apenas simulando prestar atenção. Buscamos compreender tal falha a partir de algo conjuntural. O exercício literário - aquele em que se descobre o sabor da literaturaocorre a partir de um trabalho imaginativo e reflexivo. Pensamos que os hábitos contemporâneos - demasiados objetivos e positivistas - não favorecem o exercício mental imaginativo e reflexivo. A própria lógica objetivista dos vestibulares não possibilita um espaço para que se possa provar a literatura. Dentro desse contexto, o professor falhou com alguns alunos ao tentar apresentar a prática literária.

Outro aspecto que se deve mencionar a esse respeito é o que tange à psicanálise. Acredita-se que boa parte dos alunos está com grande parcela de seu investimento libidinal voltado para questões que envolvem recalques e incompreensões acerca do próprio ser, seja de ordem sexual ou de relações com outros indivíduos. Tal observação ressalta a importância de um atendimento psicológico que propicie o bem-estar mental dos alunos. Esse exercício mostra-se complexo por envolver ações amplas. Acreditamos que para um ambiente de aula mais aproveitável, no qual os alunos compreendam melhor suas questões internas, deve haver aceitação e não preconceito. Isso envolve desde o respeito pelas questões raciais e de orientação sexual até a valorização igualitária dos sexos. O respeito à diferença propicia um ambiente escolar mais saudável, de modo a refletir diretamente no rendimento das aulas.

A literatura possui múltiplos efeitos e, portanto, torna-se delicado seu ensino. Os alunos precisam ver a linguagem como algo em que os significantes e os significados são móveis e não fixos. Precisam pensar criticamente na noção de verdade, questionando até sua existência, refletindo se é algo natural ou cultural, imposto por aqueles que detêm o poder. As aulas de literatura precisam abordar questões delicadas, desde a orientação sexual até as questões raciais e religiosas. Para que isso ocorra com naturalidade, os alunos precisam estar dispostos a sair de um lugar de julgamento e dar vasão a novos pontos de vista. Sendo assim, muitas vezes, sobretudo no que toca às questões religiosas, a matéria literária torna-se difícil de ser abordada, porém, ainda que promovendo um mal-estar, deve ser trabalhada. A criação de uma ferida naquele pensamento já estabilizado proporcionará ao aluno, ainda que depois de certo tempo, uma mínima reflexão crítica.

Outro problema de ordem prática ocorreu ao juntar duas turmas. O número de alunos ultrapassou um limite controlável, instaurando certa dificuldade no prosseguimento das aulas. Além de extenuar o professor, o tempo dispendido 
ao pedir silêncio era grande. Ficou evidente que uma sala de aula não pode ser superlotada. Cada turma possui perfil e ritmos específicos. Então, para que o professor possa respeitar e trabalhar com cada perfil, bem como conhecer seus alunos enquanto sujeitos que amam, que odeiam e que sofrem, é necessário haver um número não muito grande de alunos.

Também deve haver tempo hábil para que o professor prepare o conteúdo e exercícios adequados aos seus alunos. São absolutamente indispensáveis tais exigências. Um número aceitável de alunos por turma e um tempo adequado para o professor se preparar devem ser prioridades.

\subsection{Conclusão}

Apesar de os alunos referidos estudarem apenas um ano no pré-vestibular, no ano de 2013, verificou-se a ocorrência de várias aprovações para universidades públicas. No ano de 2014, dois alunos não aprovados continuaram a se dedicar às aulas. Os alunos, neste último ano, encontravam-se motivados para passar nos exames de vestibular, ainda que, algumas vezes, não entregassem as atividades pedidas. Vê-se que um ensino não formal da literatura - isto é, aulas em que haja leituras em sala, e não somente o ensino de características de cada época - possibilitam resultados positivos.

De todo modo, os autores deste artigo acreditam que a aula de literatura trata muito mais de descoberta do que ensino, portanto, o professor funcionaria como um guia que apresenta e inicia os alunos na experiência literária. Para que tal lógica funcione, é indispensável o espaço para a reflexão e a imaginação. Tais noções são contemporaneamente coibidas pelas ideias produtivistas e positivistas que permeiam a sociedade. Concluímos que a tarefa do professor de literatura, não importa em qual série, ultrapassa os limites da escola e atinge a sociedade, promovendo feridas positivas a própria noção de ser de cada aluno.

\section{Referências}

BRASIL. Ministério da Educação. Secretaria de Educação Fundamental. Parâmetros Curriculares Nacionais: língua portuguesa, Brasília, DF, 1998.

BUARQUE, C. Sou insensato. Rio de Janeiro: Garamond, 2007.

SAVIANI, D. Da nova LDB ao Fundeb: por uma política educacional. 3. ed. São Paulo: Autores Associados, 2008. ${ }^{3}$

3 Graduando em Letras-Literatura pela Universidade Federal Fluminense. E-mail: guilhermemilner@gmail.com. 
